\title{
Indentation Creep Behavior in Ce-Based Bulk Metallic Glasses at Room Temperature
}

\author{
Bingchen Wei ${ }^{1, *}$, Taihua Zhang ${ }^{2}$, Weihuo $\mathrm{Li}^{1}$, Dongmei Xing ${ }^{2}$, \\ Lingchen Zhang ${ }^{1}$ and Yuren Wang ${ }^{1}$ \\ ${ }^{1}$ National Microgravity Laboratory, Institute of Mechanics, Chinese Academy of Sciences, Beijing 100080, P. R. China \\ ${ }^{2}$ State Key Laboratory of Nonlinear Mechanics (LNM), Institute of Mechanics, Chinese Academy of Sciences, \\ Beijing 100080, P. R. China
}

The room temperature creep behaviors of Ce-based bulk metallic glasses were examined by the use of nanoindentation. The creep rate and creep rate sensitivity of Ce-based BMGs were derived from indentation creep curves. The low creep rate sensitivity of Ce-based BMGs indicates that the room temperature creep is dominated by localized shear flow. The experimental creep curves can be described by a generalized Kelvin model. Furthermore, the creep retardation spectrum is calculated for the Ce-based metallic glasses. The results showed that creep retardation spectrum consists of two relatively separated peaks with the well defined characteristic relaxation times.

(Received June 21, 2005; Accepted August 5, 2005; Published December 15, 2005)

Keywords: bulk metallic glass, creep, nanoindentation, relaxation

\section{Introduction}

The plastic deformation during creep of metallic glasses has been widely investigated. The dependence of the shear strain rate (or viscosity) on the temperature, time, structure relaxation, and the mechanism governing this dependence has been the most active areas of research. ${ }^{1-4)}$ Isothermal creep experiments were usually performed at high temperature (approaching glass transition temperature, $T_{\mathrm{g}}$ ), where homogeneous flow takes place. Recently, rare-earth band bulk metallic glasses (BMGs) with low $T_{\mathrm{g}}$ has been developed, such as La-, Nd-, Pr-, and especially Ce-based BMGs, showing the $T_{\mathrm{g}}$ as low as $355 \mathrm{~K}^{5-8)}$ This may allow the creep experiments to be performed at room temperature, as the ratio of room temperature to $T_{\mathrm{g}}$ is higher than 0.8 in the case of Ce-based BMGs. ${ }^{8}$

Conventional creep testing requires many samples and therefore is time consuming and inconvenient. It is also difficult to build models and study mechanisms when there are sample-to-sample variations in the microstructure. Indentation creep testing has been proved to be a powerful technique for studying the rheological properties and relaxation dynamics on amorphous materials, such as polymer. ${ }^{9-14)}$ However, little work has been done on BMGs. In this paper, a pronounced creep phenomenon at room temperature in Ce-based BMGs is observed through nanoindentation tests. The room temperature creep behavior is studied.

\section{Experimental Procedures}

Ingots with a nominal composition of $\mathrm{Ce}_{60} \mathrm{Al}_{15} \mathrm{Ni}_{15} \mathrm{Cu}_{10}$ and $\mathrm{Ce}_{68} \mathrm{Al}_{10} \mathrm{Cu}_{20} \mathrm{Nb}_{2}$ were prepared by arc-melting of elements $\mathrm{Ce}, \mathrm{Al}, \mathrm{Ni}, \mathrm{Cu}$ and $\mathrm{Nb}$ with a purity of $99.9 \%$ in titanium-gettered argon atmosphere. Cylindrical specimens of $3 \mathrm{~mm}$ in diameter and $70 \mathrm{~mm}$ in length were prepared by suction casting into a copper mold. The structure of samples

*Corresponding author, E-mail: weibc@imech.ac.cn was characterized by X-ray diffraction (XRD) in a Philips PW 1050 diffractometer using $\mathrm{Cu} K \alpha$ radiation. Thermal analysis was performed with a Perkin-Elmer DSC-7 differential scanning calorimeter at heating rate $20 \mathrm{~K} / \mathrm{min}$ under argon atmosphere. The specimens were mechanically polished to a mirror finish and tested in a MTS Nano Indenter ${ }^{\circledR}$ XP with a standard Berkovich diamond tip under room temperature $(296 \mathrm{~K})$. At least six indentations were made for each test.

\section{Results and Discussion}

As-cast samples of $\mathrm{Ce}_{60} \mathrm{Al}_{15} \mathrm{Ni}_{15} \mathrm{Cu}_{10}$ and $\mathrm{Ce}_{68} \mathrm{Al}_{10^{-}}$ $\mathrm{Cu}_{20} \mathrm{Nb}_{2}$ alloys exhibit an XRD spectrum typical for the amorphous phase. The glass transition temperature $\left(T_{\mathrm{g}}\right)$, crystallization temperature $\left(T_{\mathrm{x}}\right)$, and melting temperature $\left(T_{\mathrm{m}}\right)$ for the two BMGs measured by DSC at the heating rate of $20 \mathrm{~K} / \mathrm{min}$ are listed in Table 1 . These values are in agreement with the Ce-based BMGs with the same composition. ${ }^{8)}$ The ratio of room temperature to $T_{\mathrm{g}}$ is 0.74 for $\mathrm{Ce}_{60} \mathrm{Al}_{15} \mathrm{Ni}_{15} \mathrm{Cu}_{10}$ BMG, and 0.82 for $\mathrm{Ce}_{68} \mathrm{Al}_{10} \mathrm{Cu}_{20} \mathrm{Nb}_{2}$ BMG.

Indentation creep measurements are performed by using a standard Berkovich indenter tip under load-control mode. The indentation segments include a constant loading rate segment with a duration of $5 \mathrm{~s}$ (A-B in Fig. 1), holding at the maximum load of $100 \mathrm{mN}$ for $1000 \mathrm{~s}(\mathrm{~B}-\mathrm{C})$, and then unloading to $10 \%$ of the maximum load (C-D) in $5 \mathrm{~s}$, followed by another holding at $10 \mathrm{mN}$ (D-E) for $100 \mathrm{~s}$.

Table 1 Glass transition temperature $\left(T_{\mathrm{g}}\right)$, crystallization temperature $\left(T_{\mathrm{x}}\right)$, melting temperature $\left(T_{\mathrm{m}}\right)$, hardness $(H)$ and elastic modulus $(E)$ values for $\mathrm{Ce}_{60} \mathrm{Al}_{15} \mathrm{Ni}_{15} \mathrm{Cu}_{10}$ and $\mathrm{Ce}_{68} \mathrm{Al}_{10} \mathrm{Cu}_{20} \mathrm{Nb}_{2}$ BMGs.

\begin{tabular}{cccccc}
\hline Alloys & $\begin{array}{c}T_{\mathrm{g}} \\
(\mathrm{K})\end{array}$ & $\begin{array}{c}T_{\mathrm{x}} \\
(\mathrm{K})\end{array}$ & $\begin{array}{c}T_{\mathrm{m}} \\
(\mathrm{K})\end{array}$ & $\begin{array}{c}E \\
(\mathrm{GPa})\end{array}$ & $\begin{array}{c}H \\
(\mathrm{GPa})\end{array}$ \\
\hline $\mathrm{Ce}_{60} \mathrm{Al}_{15} \mathrm{Ni}_{15} \mathrm{Cu}_{10}$ & 400 & 465 & 386 & 43.7 & 2.34 \\
$\mathrm{Ce}_{68} \mathrm{Al}_{10} \mathrm{Cu}_{20} \mathrm{Nb}_{2}$ & 359 & 412 & 385 & 37.1 & 1.69 \\
\hline
\end{tabular}




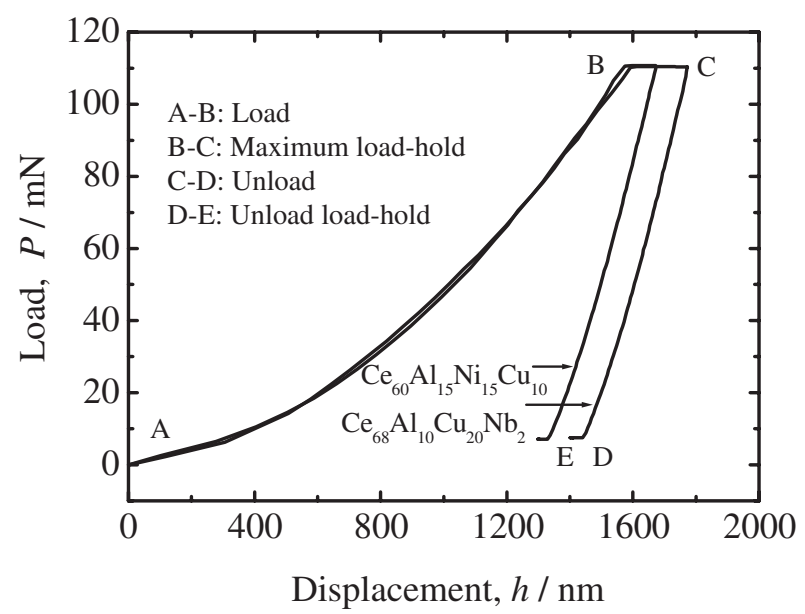

Fig. 1 Typical load-displacement $(P-h)$ curves of $\mathrm{Ce}_{60} \mathrm{Al}_{15} \mathrm{Ni}_{15} \mathrm{Cu}_{10}$ and $\mathrm{Ce}_{68} \mathrm{Al}_{10} \mathrm{Cu}_{20} \mathrm{Nb}_{2}$ BMGs during the indentation creep experiments. A-E showing the nanoindentation procedure.

Typical load-displacement $(P-h)$ curves during nanoindentations creep measurements of the two BMGs are presented in Fig. 1. It can be seen that, a pronounced creep displacement is observed during the holding load segment at the maximum load in the two BMGs. The total creep displacement at this segment is 86 and $159 \mathrm{~nm}$ for $\mathrm{Ce}_{60} \mathrm{Al}_{15} \mathrm{Ni}_{15} \mathrm{Cu}_{10}$ BMG and $\mathrm{Ce}_{68} \mathrm{Al}_{10} \mathrm{Cu}_{20} \mathrm{Nb}_{2}$ BMG, respectively. A less pronounced creep displacement can be found during the second holding load segment (D-E) in the two BMGs. To our knowledge, the room temperature creep in BMGs has not been previously reported. The elastic modulus $(E)$ and the hardness $(H)$ of the two BMGs can be obtained using OliverPharr method, and the results are also listed in Table 1. The elastic modulus value obtained from nanoindentation agrees well with that from acoustic test. ${ }^{8)}$

Figure 2 shows the creep displacement versus time $(h-t)$ curves of $\mathrm{Ce}_{60} \mathrm{Al}_{15} \mathrm{Ni}_{15} \mathrm{Cu}_{10}$ and $\mathrm{Ce}_{68} \mathrm{Al}_{10} \mathrm{Cu}_{20} \mathrm{Nb}_{2}$ BMGs. There are usually three stages during a conventional tensile creep experiment. The tertiary stage of creep in materials leads to fracture. This is different from an indentation

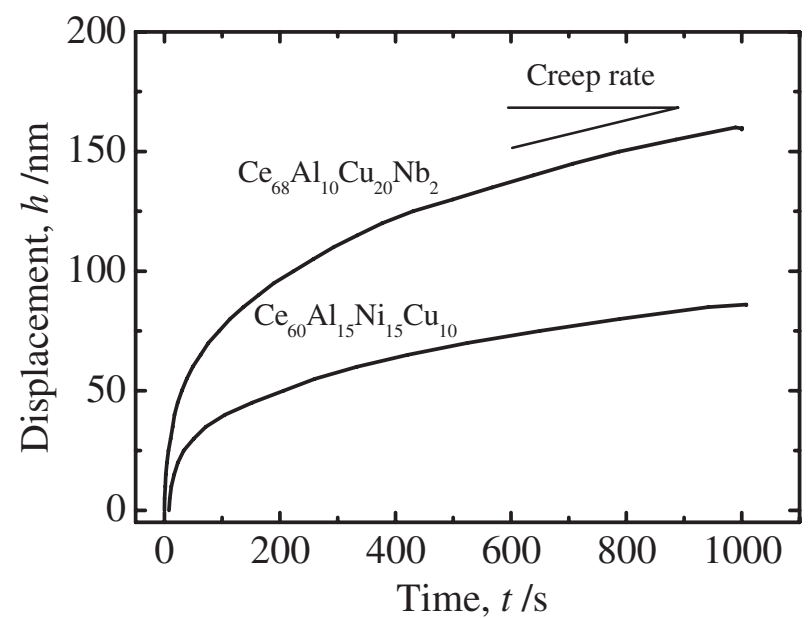

Fig. 2 Creep displacement-time $(h-t)$ curves of $\mathrm{Ce}_{60} \mathrm{Al}_{15} \mathrm{Ni}_{15} \mathrm{Cu}_{10}$ and $\mathrm{Ce}_{68} \mathrm{Al}_{10} \mathrm{Cu}_{20} \mathrm{Nb}_{2}$ BMGs. experiment, in which the indentation load only leads to the primary and the secondary stage of creep for amorphous materials. In general, the fracture cannot be observed during indentation creep experiments. The creep rates calculated from the secondary creep stage in Fig. 2 are 0.039 and $0.080 \mathrm{~nm} / \mathrm{s}$ for $\mathrm{Ce}_{60} \mathrm{Al}_{15} \mathrm{Ni}_{15} \mathrm{Cu}_{10}$ and $\mathrm{Ce}_{68} \mathrm{Al}_{10} \mathrm{Cu}_{20} \mathrm{Nb}_{2}$ BMGs, respectively. For a steady-state creep, the relationship between the indentation strain rate, $\dot{\varepsilon}$, and the hardness, $H$, at a constant temperature can be expressed by the power-law creep: ${ }^{15)}$

$$
H=C_{1}\left(\dot{\varepsilon}_{i}\right)^{m}
$$

where $C_{1}$ is a constant, $m$ is the steady-state creep rate sensitivity, $\dot{\varepsilon}_{i}$ is defined as the indentation strain rate which can be expressed as:

$$
\dot{\varepsilon}_{i}=(\mathrm{d} h / \mathrm{d} t) / h
$$

where $h$ is indenter penetration depth, and $t$ is time. According to eq. (1) and eq. (2), the creep rate sensitivity $m$ is $\lg H / \lg \dot{\varepsilon}_{i}$. Figure 3 shows the logarithmic plots of hardness versus strain rate. The slopes of the straight lines in Fig. 3 represent the strain rate sensitivity exponent, $m$, which is 0.016 and 0.028 for $\mathrm{Ce}_{60} \mathrm{Al}_{15} \mathrm{Ni}_{15} \mathrm{Cu}_{10}$ and $\mathrm{Ce}_{68} \mathrm{Al}_{10^{-}}$ $\mathrm{Cu}_{20} \mathrm{Nb}_{2} \mathrm{BMG}$, respectively. If $m=1$, the flow is Newtonian; $m<1$ indicates inhomogeneous non-Newtonian flow. This quite low $m$ values in the present BMGs is attributed to the strongly localized shear flow.

A high loading rate of $20 \mathrm{mN} / \mathrm{s}$ was chosen to minimize the viscoelastic deformation during the loading segment in the present indentation creep measurements. The viscoelastic deformation takes place mainly in the holding load segments. Generally speaking, the viscoelastic behavior of the amorphous alloys can be described by a series of dashpots and linear springs known as the Kelvin model. In the present case, we use a generalized Kelvin model to fit the creep curves. ${ }^{16)}$ The total displacement $h$ during the indentation creep is expressed as:

$$
h=h_{\mathrm{e}}+\sum_{i=1}^{n} h_{\mathrm{i}}\left(1-e^{-t / \tau_{\mathrm{i}}}\right)+t / \mu_{0}
$$

where $h_{\mathrm{e}}$ is the indentation depth at the first spring, $\mu_{0}$ is a

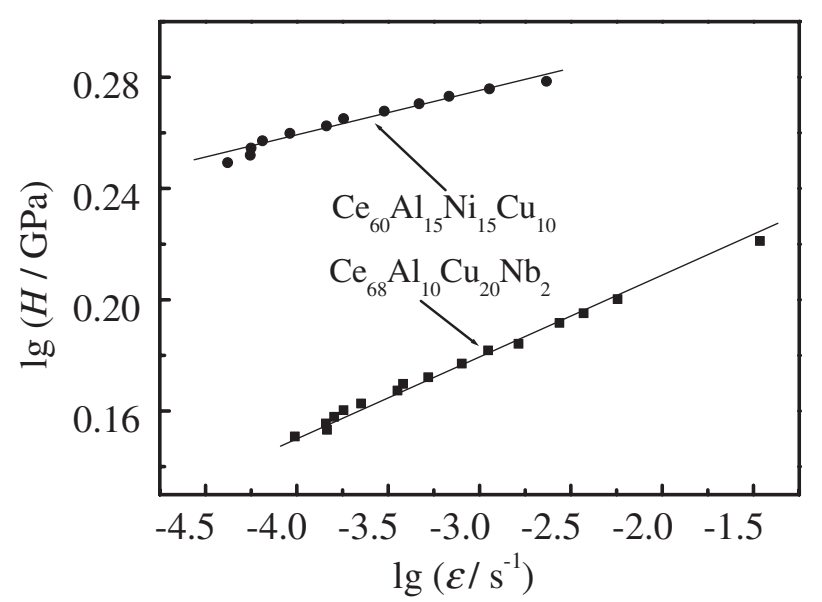

Fig. 3 Double logarithmic plot of hardness versus indentation strain rate for $\mathrm{Ce}_{68} \mathrm{Al}_{10} \mathrm{Cu}_{20} \mathrm{Nb}_{2} \mathrm{BMG}$. 
Table 2 Fitting parameters in eq. (4) for the two BMGs.

\begin{tabular}{cccccc}
\hline Alloys & $\begin{array}{c}h_{\mathrm{e}} \\
(\mathrm{nm})\end{array}$ & $\begin{array}{c}h_{1} \\
(\mathrm{~nm})\end{array}$ & $\begin{array}{c}\tau_{1} \\
(\mathrm{~s})\end{array}$ & $\begin{array}{c}h_{2} \\
(\mathrm{~nm})\end{array}$ & $\begin{array}{c}\tau_{2} \\
(\mathrm{~s})\end{array}$ \\
\hline $\mathrm{Ce}_{60} \mathrm{Al}_{15} \mathrm{Ni}_{15} \mathrm{Cu}_{10}$ & 1591.7 & 32.0 & 35.4 & 68.5 & 649.1 \\
$\mathrm{Ce}_{68} \mathrm{Al}_{10} \mathrm{Cu}_{20} \mathrm{Nb}_{2}$ & 1770.6 & 59.6 & 32.9 & 120.1 & 566.0 \\
\hline
\end{tabular}

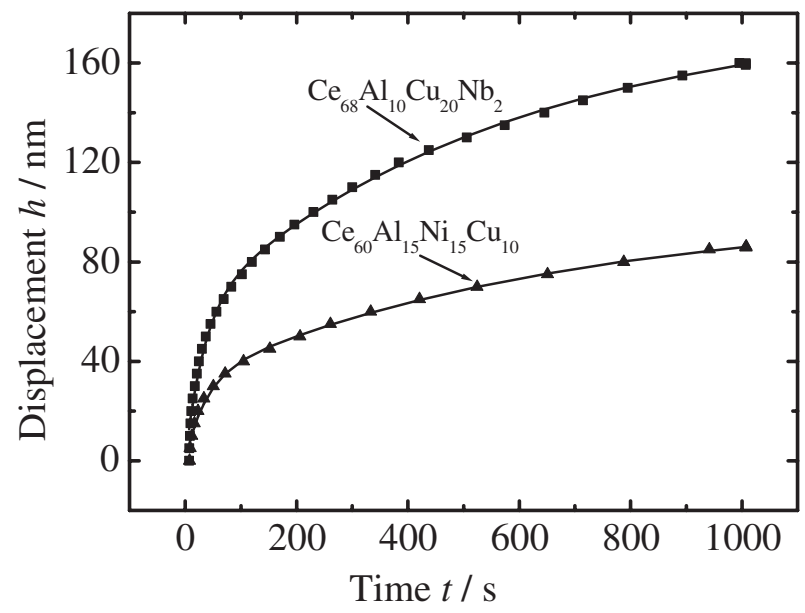

Fig. 4 Creep displacement versus time of Ce-based BMGs. The data points are experimental data and the solid lines are curve fitting by eqs. (4) with two exponential terms.

constant related to the viscosity coefficient of the last dashpot, $h_{\mathrm{i}}$ represents the indentation depth at the $i$ th Kelvin element and $\tau_{\mathrm{i}}$ is the retardation time for the $i$ th element. Furthermore, we can take no account of viscous flow at room temperature for the present BMGs, as it is not observed in the uniaxial compressive test at the comparable strain rates. So the equation (3) can be expressed a simplified form as:

$$
h=h_{\mathrm{e}}+\sum_{i=1}^{n} h_{\mathrm{i}}\left(1-e^{-t / \tau_{\mathrm{i}}}\right)
$$

The indentation creep curves of Ce-based BMGs and the fitting curves derived from eq. (4) are shown in Fig. 4. The fitting parameters are summarized in Table 2. The results show that an excellent agreement between the experimental data and the predictions of eq. (4) can be obtained by only twice fitting. The retardation times, $\tau_{1}$ and $\tau_{2}$ are the different time responses, which should reflect the influence of the amorphous structure on the indentation load. It should be pointed that the fitting is much simpler for BMGs than for polymers, such as PMMA, PET and Epoxy, etc. ${ }^{12)}$ This indicates a much simpler relaxation process in BMGs, compared with that in polymers.

From Fig. 4 we can also deduce the creep retardation spectrum, which can be approximately expressed as ${ }^{17)}$

$$
\begin{aligned}
L(\tau)= & {\left[\left(1+\frac{t}{\tau_{1}}\right) \frac{h_{1}}{\tau_{1}} e^{-t / \tau_{1}}\right.} \\
& \left.+\left(1+\frac{t}{\tau_{2}}\right) \frac{h_{2}}{\tau_{2}} e^{-t / \tau_{2}}\right]\left.\frac{A_{0}}{P_{0} h_{\mathrm{in}}} t\right|_{t=2 \tau}
\end{aligned}
$$

The retardation spectra of the Ce-based BMGs are shown

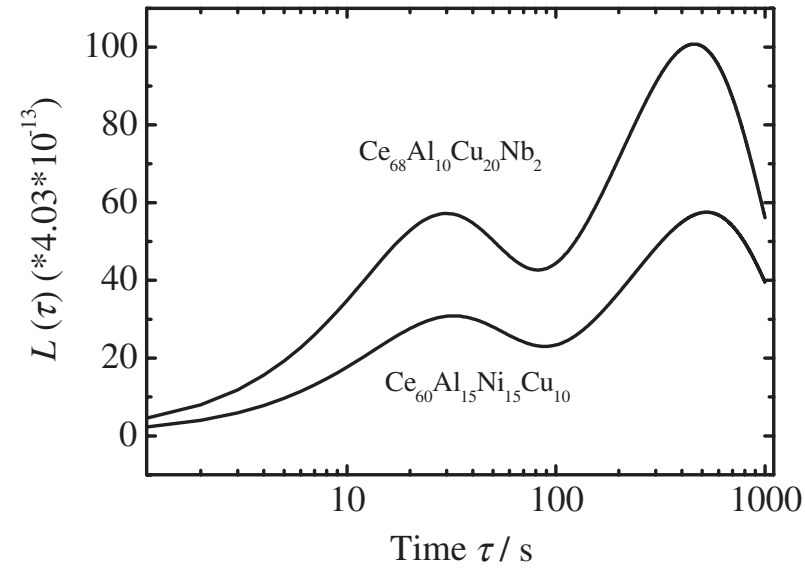

Fig. 5 Retardation spectrum for $\mathrm{Ce}_{60} \mathrm{Al}_{15} \mathrm{Ni}_{15} \mathrm{Cu}_{10}$ and $\mathrm{Ce}_{68} \mathrm{Al}_{10} \mathrm{Cu}_{20} \mathrm{Nb}_{2}$ $\mathrm{BMGs}$ from eqs. (5) derived from nanoindnetation creep experiments.

in Fig. 5. It is revealed that each creep relaxation spectrum consists of two relatively separated peaks with the well defined characteristic relaxation times. This implies two kinds of relaxation processes for Ce-based BMGs during indentation creep at room temperature. The relatively sharper retardation peak is observed in $\mathrm{Ce}_{68} \mathrm{Al}_{10} \mathrm{Cu}_{20} \mathrm{Nb}_{2} \mathrm{BMG}$ than in $\mathrm{Ce}_{60} \mathrm{Al}_{15} \mathrm{Ni}_{15} \mathrm{Cu}_{10}$ BMG. This indicates that the former $\mathrm{BMG}$ is in a more relaxed state. The two broad retardation peaks suggest that the activation processes of the shear transformation in the Ce-based BMGs have a distribution of activation free energies. $\mathrm{Li}$ and Warren proposed that the stress fields in the material beneath the indenter create a chemical potential gradient that leads to thermally activated diffusional flux of atoms. ${ }^{18)}$ Aklonis employed two relaxation times to describe the relaxation process near the glass transition or sub- $T_{\mathrm{g}}$ region. ${ }^{19)}$ The two relaxation processes were correlated to chemical short-range order (CSRO) and topologic short-range order (TSRO) in the processes of relaxation for amorphous alloys. Csach et al. reported three well-defined peaks in relaxation time spectrum for $\mathrm{Fe}_{40} \mathrm{Ni}_{40} \mathrm{~B}_{20}$ and $\mathrm{Ni}_{77.5} \mathrm{Si}_{7.5} \mathrm{~B}_{15}$ amorphous ribbons. ${ }^{20)}$ Each of the peaks represents a different material transport mechanism or distinct type of flow defects in the amorphous structure. The flow defects is termed as non-coincident atomic sites configuration that are located at intercluster boundaries may be considered as similar to atomic configurations of dislocation cores in crystals. Obviously, further work is necessary to understand how does this phenomenon relate to materials characteristics in the present BMGs.

\section{Conclusions}

In summary, room temperature creep behavior of $\mathrm{Ce}_{60} \mathrm{Al}_{15} \mathrm{Ni}_{15} \mathrm{Cu}_{10}$ and $\mathrm{Ce}_{68} \mathrm{Al}_{10} \mathrm{Cu}_{20} \mathrm{Nb}_{2}$ BMGs with quite low glass transition temperatures was probed by indentation creep measurements. The creep rate sensitivity is 0.016 for the former $\mathrm{BMG}$ and 0.028 for the later BMG. The indentation creep behavior of the Ce-based BMGs can be well described by a generalized Kelvin model. The creep relaxation spectrum reveals two separated peaks, which indicate two kinds of relaxation processes for Ce-based $\mathrm{BMGs}$ during indentation creep at room temperature. 


\section{Acknowledgements}

The authors would like to acknowledge the financial support provided by National Nature Science Foundation of China (Grant Nos. 50571109, 10372103 and 10432050) and the Knowledge Innovation Program of Chinese Academy of Sciences.

\section{REFERENCES}

1) H. Kato, A. Inoue and H. S. Chen: Appl. Phys. Lett. 79 (2001) 45154517.

2) W. L. Johnson, J. Lu and M. D. Demetriou: Intermetallics 10 (2002) 1039-1046.

3) M. Ohta, A. E. Berlev, V. A. Khonik and K. Kitagawa: Philos. Mag. 83 (2003) 3463-3471.

4) A. E. Berlev, O. P. Bobrov, V. A. Khonik, K. Csach, A. Juríková, J. Miškuf, H. Neuhäuser and M. Yu. Yazvitsky: Phys. Rev. B 68 (2003) 132203.

5) A. Inoue, T. Zhang and T. Masumoto: Mater. Trans., JIM. 30 (1990) 425-428.

6) Y. He, C. E. Price, S. J. Poon and G. J. Shiflet: Phlios. Mag. Lett. 70
(1994) 371-377.

7) Z. F. Zhao, P. Wen, M. X. Pan, D. Q. Zhao and W. H. Wang: Appl. Phys. Lett. 82 (2003) 4699-4601.

8) B. Zhang, M. X. Pan, D. Q. Zhao and W. H. Wang: Appl. Phys. Lett. 85 (2004) 61-63.

9) B. J. Briscoe, K. S. Sebastian and M. J. Adams: J. Phys. D 27 (1994) 1156-1162.

10) B. J. Briscoe, L. Fiori and E. Pelillo: J. Phys. D 31 (1998) 2395-2405.

11) A. Strojny and W. W. Gerberich: Mater. Res. Soc. Symp. Proc. 522 (1998) 159-164.

12) J. C. M. Li: Mater. Sci. Eng. A 322 (2002) 23-42.

13) M. L. Oyen and R. F. Cook: J. Mater. Res. 18 (2003) 139-150.

14) Y. Shuang, Y. W. Zhang and K. Y. Zeng: J. Appl. Phys. 95 (2004) 3655-3666.

15) A. C. Fishcher-Cripps: Nanoindentation (Springer, New York, 2000) pp. 111-113.

16) D. Y. Chiang, P. C. Crary and J. C. M. Li: Polymer 35 (1994) 41034109.

17) P. M. Sargent and M. F. Ashby: Mater. Sci. Technol. 8 (1992) 594-601.

18) W. B. Li and R. Warren: Acta. Metall. Mater. 41 (1993) 3065-3069.

19) J. J. Aklonis and A. J. Kovacs: Contemp. Top. Polym. Sci. 3 (1979) 267-272.

20) V. Ocelík, K. Csach, A. Kasardová and V. Z. Bengus: Mater. Sci. Eng. A 226-228 (1997) 851-855. 